DOI: 10.17805/ggz.2018.2.7

\title{
Свободное время столичных жителей в условиях современной реальности: отдых в парковых зонах города Москвы
}

О. Л. Лебедь

Первый Московский государственньй медииинский университет имени И. М. Сеченова Минздрава России, А. Н. Пинчук

Институт социально-политических исследований РАН, г. Москва, С. В. Ляликова

Московский государственный университет имени М. В. Ломоносова

Сегодня свободное время приобретает все больмее значение в жизни современных людей, занимая возрастающую долю в структуре повседневного времени. Однако, представляя динамично развивающийся сочиокультурный феномен, свободное время приобретает новые черты, смещаясь в сферу потребления. В этих условиях снижается потенциал рекреационного поведения населения как способа отдыха и восстановления здоровья. Соииокультурные и эколого-климатические условия проживания в столичном мегаполисе значительно актуализируют проблему массового распространения культурно-оздоровительного отдыха. Московские парковые комплексы имеют основательную материально-техническую базу для проведения свободного времени с пользой для здоровья.

В статье представлены результаты фокус-групповых интервью посетителей столичных парков. Описаны причины посещения парков, целевая аудитория, поведение в парке, получены рекомендации жителей для усовершенствования парковых зон. Выявлено, что особенности поведения на территории парка свидетельствуют о потребительской ориентации на видь досуга в парке.

Ключевые слова: свободное время; здоровьеориентированные практики; парковые зоны; фокус-групповое интервью; московские парки 


\section{Free Time of Metropolitans in the \\ Conditions of Modern Reality: Rest in the Park Areas of the City of Moscow}

O. L. Lebed

I. M. Sechenov First Moscow State Medical University,

A. N. Pinchuk

Institute of Socio-Political Research, Russian Academy of Sciences, Moscow,

S. V. Lyalikova

Lomonosov Moscow State University

Nowadays, free time becomes more and more important in the life of contemporary people, occupying an increasing share in the structure of everyday time. However, being a dynamically developing socio-cultural phenomenon, free time has acquired new features, shifting into the sphere of consumption. Under these conditions, the potential of recreational behavior of the population as a means of recreation and recovery of health is reduced. Socio-cultural and ecologicalclimatic conditions of living in the Moscow megalopolis significantly actualize the problem of mass distribution of cultural and health-improving rest. Moscow park complexes have a solid material and technical base for spending free time healthily.

The article presents the results of focus-group interviews with visitors of the Russian capital's parks. The authors describe the reasons of visiting parks, their target audience, behavior in parks. Recommendations of residents concerning improvement of park zones were received. It is revealed that the peculiarities of behavior in parks indicate the consumer orientation to leisure activities in parks.

Keywords: free time; health-oriented practices; park areas; focus-group interview; Moscow parks

\section{ВВЕДЕНИЕ}

В условиях ускоряющихся темпов развития научно-технического прогресса, повышения жизненного уровня населения и сокращения времени необходимого труда все большее значение приобретает феномен свободного времени. Представляя динамично развивающееся социальное явление, свободное время выполняет ряд важных функций, среди которых рекреационная функция играет определяющую роль в поддержании и восстановлении общественного здоровья. Все это обуславливает интерес к содержанию свободного времени жителей столичного мегаполиса, которые особенно нуждаются в правильном отдыхе для сохранения и укрепления здоровья. Находясь посто- 
янно под воздействием различных негативных факторов (ускоренный ритм жизни, частые стрессовые ситуации, неблагоприятная экологическая обстановка), население столицы сталкивается с необходимостью освоения практик спортивно-оздоровительного досуга в связи с повышенными нагрузками на здоровье. Однако в современном обществе свободное время становится общедоступной культурной ценностью, неразрывно связанной со сферой потребления, удовольствий и развлечений. Проблема в том, что условия проживания в столичном мегаполисе отличает высокая концентрация досуговых центров, стимулирующих отдых развлекательной и пассивной направленности, что может служить основой для смещения оздоровительного отдыха на второй план. Рассмотрение сложившейся ситуации в медико-социальном аспекте привлекает особое внимание к поведению московских жителей в свободное время, когда, с одной стороны, активно популяризируется здоровый образ жизни и предпринимаются соответствующие меры для его реализации, a, с другой, открывается широкий спектр возможностей для пассивного и развлекательного отдыха, в том числе, в сфере рекреационных услуг.

\section{СВОБОДНОЕ ВРЕМЯ КАК СОЦИОКУЛЬТУРНЫЙ ФЕНОМЕН}

Очерчивая теоретическую рамку изучения феномена свободного времени, отметим достаточно основательную проработанность обозначенной тематики в массиве накопленных материалов и исследований, представленных трудами зарубежных (Т. Веблен, А. Ллойд, Дж. Ландберг, М. Каплан, К. Робертс, Ж. Дюмазедье, Ж. Фурастье, Э. Гросс, С. Паркер и др.) и отечественных авторов (С. Г. Струмилин, В. Д. Патрушев, Б. А. Грушин, Э. В. Соколов, Г. П. Орлов, Г. Е. Зборовский и др.).

Следует заметить, что обширная практика использования понятий «свободное время» и «досуг» привела к частичному размыванию терминологических границ между ними. В этом случае предлагаем ориентироваться на определение, представленное в Социологической энциклопедии, где уточняется, что досуг является частью свободного времени, а само свободное время - это «часть времени суток, свободная от труда в общественном хозяйстве и связанного с ним времени удовлетворения физиологических и бытовых потребностей и домашнего труда» (Социологическая энциклопедия, 2003: 178).

Артикулируя свободное время в жизни современного индивида, нельзя не отметить все возрастающее многообразие досуговых практик и увеличивающуюся долю самого досуга в структуре повседневного времени нынешнего поколения. Данное положение дел фокусирует исследовательское внимание на содержании свободного времени, которое включает затраты на ви- 
ды занятий, связанных с общением, творчеством, учебой, спортом, общественной работой, посещением культурных мероприятий и т. д. (Тощенко, Цветкова, 2012: 207). Если рассматривать содержание свободного времени нынешнего поколения, то стоит отметить изменения в досуговых практиках современных россиян, что показывают данные массовых опросов ВЦИОМ (метод опроса - телефонное интервью, выборка - стратифицированная двухосновная случайная выборка стационарных и мобильных номеров, объем выборки - 1200 респондентов). Так, в последнее время неуклонно растет доля тех, кто предпочитает в свободное время заниматься домашним хозяйством, детьми, дачей (40\% в 2005 г., 60 \% в 2017 г.), общаться с друзьями дома или в гостях (23\% в 2005 г., 30 \% в 2017 г.), либо заниматься хобби (7\% в 2005 г. и $26 \%$ в 2017 г.).

Примечательно, что также увеличился процент любителей отдыха на природе, их число выросло почти вдвое (13 \% в 2005 г., 34 \% в 2017 г.), в то время как, сократилось количество респондентов, которые обычно смотрят телевизор или слушают радио (45 \% в 2005 г. и 29 \% в 2017 г.) (А на досуге ... , 2017: Электронный ресурс).

Итак, сегодня фиксируются положительные сдвиги в динамике досуга современных россиян в сторону популяризации отдыха на природе, что заставляет задуматься о возможностях городской среды для реализации данного вида досуга. Очевидными преимуществами для культурно-оздоровительного отдыха на природе обладают парковые комплексы, представляющие основательную материально-техническую базу для массовизации здоровьеориентированных практик горожан.

\section{ПАРКОВЫЕ ЗОНЫ КАК ПЛАТФОРМА ДЛЯ РЕАЛИЗАЦИИ ЗДОРО- ВЬЕСБЕРЕГАЮЩИХ ПРАКТИК}

О социальной значимости и востребованности развития парковых зон в столичном мегаполисе свидетельствуют основные цели Государственной программы города Москвы «Развитие городской среды», где благоустройство парковых зон становится ключевым направлением в организации отдыха и досуга населения (Государственная программа ... , 2017: Электронный pecypc).

Стоит отметить, что в результате реализации первых этапов Государственной программы посещаемость московских парков культуры и отдыха увеличилась в 4 раза, а доля посетителей, охваченных культурно-досуговыми и спортивно-оздоровительными услугами, в 2016 году достигла 62 \%, что не является пределом. Так, на последнем этапе осуществления целей и задач Государственной программы «Развитие городской среды» в 2019 г. планиру- 
ется увеличить количество посещений парков в 4,2 раза, а количество посетителей — в 8,3 раза (там же).

Всплеск интереса к отдыху в парках среди москвичей фиксируют в последние годы и социологические службы. Так, по данным опроса ФОМ, осуществленного в 2016 г. совместно с КБ «Стрелка» (выборка - 4000 респондентов в возрасте 18 лет и старше), самым распространенным местом отдыха для московских жителей оказались городские парки: 52 \% (среди молодежи 78 \%) посещают парки не реже, чем несколько раз в месяц (Самым популярным ..., 2016: Электронный ресурс).

Таким образом, современный городской парк становится открытой платформой для реализации физкультурно-оздоровительных, спортивных, культурно-образовательных мероприятий, представляя организованный комплекс досуговых услуг для поддержания и укрепления общественного здоровья. Это подтверждается и комплексом мер, осуществляемых городской властью, и повышением популярности парка как места отдыха среди московского населения. Однако, если обратить внимание на широкие возможности парка для проведения свободного времени исключительно с пользой для здоровья, то остается открытым вопрос, как реально проводят свободное время в парках жители и гости столицы? Иными словами, посещение парковых комплексов может носить пассивный и развлекательный характер, что снижает потенциал рекреационного поведения в парках. Ведь ориентация на комфорт, как основная черта общества потребления, может отразиться и на практиках досуга в парках. Так, о чем же свидетельствует все увеличивающаяся доля посетителей современных парковых зон - о массовом распространении физкультурно-оздоровительных досуговых практик или о пассивном и развлекательном отдыхе на природе?

Цель данной статьи - выявление особенностей проведения свободного времени жителями Москвы в городских парках.

\section{ОСОБЕННОСТИ ПРОВЕДЕНИЯ СВОБОДНОГО ВРЕМЕНИ В МОСКОВСКИХ ПАРКАХ ЖИТЕЛЯМИ СТОЛИЦЫ}

С целью исследования практик посещения в свободное время московских парков и выявления потребностей и запросов посетителей к современному городскому парку в июле 2017 г. было проведено 6 фокус-групп. Описываемые фокус-группы являлись частью более крупного социологического исследования маршрутов, ожиданий и предпочтений москвичей в парковых зонах города, охватившего практически всю территорию столицы (16 парков города). 
Группы были сформированы на основе принципа половозрастной гомогенности и включали следующие возрастные категории: 18-25 лет; 26-35 лет; 36-55 лет; родители/родственники, посещающие парк с детьми до 12 лет; 55 лет и старше (2 фокус-группы).

В рамках сформированных фокус-групп обсуждались следующие темы: причины посещения парка; частота посещения парка разными целевыми аудиториями; конкурентные преимущества парка по сравнению с другими местами отдыха и развлечений; поведение в парке (маршруты, виды деятельности, участие в различных мероприятиях, оценка объектов и услуг парка); рекомендации для усовершенствования территории городского парка.

Проведенное исследование показало, что москвичи и гости столицы знают и с удовольствием посещают городские парки в качестве мест отдыха. К наиболее популярным паркам, которые отметили участники фокус-групп, относятся государственный музей-заповедник «Царицыно», Московский объединенный музей-заповедник «Коломенское», Центральный парк культуры и отдыха (ЦПКиО) имени Горького, парки «ВДНХ», «Сокольники», «Лосиный остров», «Фили», «Сосновый Бор», «Измайловский», «Кусково», «Терлецкий» и др.

Московские парки привлекают респондентов возможностью отдохнуть от городской среды, насладиться покоем, чистым воздухом, полюбоваться природой, погулять с близкими. Не менее значимую привлекательность для посетителей парков составляют сезонные виды отдыха и развлечений. Летом, как правило, пляж, лодки, катамараны, зимой - лыжи, коньки, горки и прочеe.

Многих горожан к посещению парков мотивирует культурная и спортивная составляющие парковой зоны: наличие развлечений, как для детей, так и для взрослых; тренажеры и площадки для занятий спортом; ухоженные ландшафты; места для чтения и настольных игр; памятники истории (например, в парках «Кусково», «Царицыно», «Сокольники», «Парк Победы», «ВДНХ», «Фили» и т. д.).

Многообразие возможностей для отдыха в парке подчеркивали и сами респонденты: «В парках гуляю очень часто, зимой и летом, с разными целями, со спортом, с отдыхом, концерт посмотреть, с детьми» (женщина, 26-35 лет).

Следует заметить, что в последние годы пожилые и люди более молодого возраста рассматривают парки как альтернативу даче, особенно, когда погода не позволяет выезжать на дачу надолго. Как объяснила одна из участниц исследования, «...сейчас уже все поняли, что парк столько предлагает всего красивого, здесь удовольствие получаешь, не хуже, чем на даче. Зато 
погулял - пришел домой, уже в квартире, уже - все удобства...» (женщина, 55 лет и старше).

Для некоторых столичных жителей парк является комфортной зоной для встреч с близкими людьми: «Я прихожу и с дочерью повидаться, и почитать, и посидеть, и погулять, и на народ посмотреть» (женщина, 55 лет и старше).

Отношение к парку, как к месту отдыха и встреч, в одном случае можно объяснить высокой степенью удовлетворенности организационнокультурными и рекреационными условиями парка, в другом, - территориальной близостью парка к месту жительства его посетителей (иногда респонденты указывали, что они живут рядом). Например, одна из участниц фокусгруппового интервью, будучи местной жительницей, ответила: «Я, коренная перовчанка, тут родилась, сама в детстве ходила в этот парк, каталась на лыжах от школы, нас водили. Видела с самого начала его развитие, мама нас с сестрой водила сюда гулять...» (женщина, 36-55 лет).

В этой связи стоит отметить, что большинство посетителей парка составляют жители района, близлежащих домов и улиц. Однако есть и небольшая группа людей, которые приезжают в тот или иной парк из других районов по различным причинам: прогулки с детьми, общение с друзьями; доступные цены на детские аттракционы; по причине переживаний, связанных с ностальгией, воспоминаниями.

Какова целевая аудитория московских парков? Проведенное исследование показывает, что в первой половине дня парки становятся местом для прогулок в основном мам, бабушек или нянь с детьми дошкольного возраста и для людей пожилого возраста. В вечернее время парки привлекают молодежь и людей среднего возраста, дающие возможность отдохнуть от суеты рабочего дня, успокоиться, подышать свежим воздухом.

В летний период, в дни школьных каникул и выходные возрастной состав посетителей значительно шире в любое время дня. Участники фокусгрупп нередко подчеркивали, что в летний период гулять в парках гораздо комфортнее, чем в остальные сезоны, поэтому летом посещают парк часто.

«Мы чаще всего летом гуляем в парке, ну весной, осенью реже, зимой еще соответственно реже, потому что все-таки, когда холодно, тяжелее выйти на улицу...» (женщина, 36-55 лет).

Зимой основную массу посетителей составляют родители (няни, бабушки и т. д.) с детьми и приверженцы скорее активного, чем спортивного отдыха, а именно: любители покататься на коньках, лыжах, санках, поиграть в снежки или покататься с горки. 
Несмотря на то, что аудитория парка варьируется в зависимости от сезона, можно выделить ту долю респондентов, для которой парк стал неотьемлемой частью повседневной жизни и излюбленным местом для прогулок в любое время года: «Мы живём здесь рядом. <..> Мы гуляем летом, зимой, осенью, весной. В любое время года, в любую погоду...» (женщина, 18-25 лет).

Примечательно и то, что для многих московских жителей парк приобрел особую значимость в пространстве личностных смыслов, став атрибутом родных, привычных мест. Так, участники фокус-групп, которые проводились в Парке культуры и отдыха «Перовский», указывали, что для них это «семейный, близкий, родной», «камерный парк, как раз для ежедневного времяпрепровождения», «меняющийся вместе с городом и жизнью в стране в целом».

В рамках фокус-групповой дискуссии удалось выяснить, что обычно посетители проводят в парке 1-2 часа. В некоторых случаях фиксировалась продолжительность пребывания в течение нескольких часов либо 5-6 часов и более, когда приезжают «на весь день».

Городские парки, безусловно, являются одной из ключевых зон для пеших прогулок, что способствует укреплению и поддержанию здоровья. Между тем универсальных, стандартных маршрутов для посетителей парка не существует, что удалось выяснить в ходе проведения фокус-групп. Как правило, посетители гуляют в разных направлениях, выбирая наиболее привлекательные маршруты в зависимости от настроения и цели посещения парка. К наиболее популярным у посетителей мест в парке относятся центральная часть, многочисленные аллеи, немноголюдные зоны, где можно отдохнуть в тишине, а также зона для пикников, территория около реки, около воды, пляжная зона.

Можно также отметить, что каждая категория посетителей парка выбирает те зоны и участки, которое в наибольшей степени удовлетворяют имеющимся потребностям и предпочтениям (мамы и няни - детские площадки и зону аттракционов, пенсионеры - аллеи, где есть скамейки, приверженцы активных форм отдыха - площадки с тренажерами, скейт-зоны, велодорожки).

Обращает на себя внимание следующая ситуация. Несмотря на то, что спортивная составляющая представлена достаточно широким перечнем услуг (тренажеры, прокат велосипедов, стадион, скейт-зона, занятия танцами, йогой и др.), фиксируется неполное использование ресурсов парка в культурнооздоровительных практиках посетителей. Об это свидетельствует то, что практически ни один из участников фокус-групп не тренируется регулярно, 
под руководством тренера или самостоятельно. Вместе с тем горожане высоко оценили уровень оснащения парковой зоны спортивным инвентарем и развитую систему досуговых услуг (танцы, йога), что демонстрируют следующие высказывания:

- «Нравится, что стали выставлять столы для настольного тенниса, можно поиграть не только детям, но и взрослым. Еще там, на севере для скейтбордистов построили площадку, ее завершили, дети с удовольствием играют...» (мужчина, 55 лет и старше).

- «А для взрослых есть йога, проходит два раза в неделю. В связи с тем, что плохая погода, ее иногда отменяют, потому что она проходит на свежем воздухе» (женщина, 36-55 лет).

Среди предоставляемых парком культурных развлечений можно отметить различные кружки для детей, проведение тематических фотовыставок, организацию праздничных мероприятий, которые посетители достаточно положительно оценивают и нередко в них участвуют:

- «В Перовском парке есть сайт Перовского парка, куда выкладываются фотографии, видео с праздников, недавно была высадка огорода. Дети сами сажали, сами выращивали и сами же пробовали это. В этом плане парк хорошо работает» (женщина, 26-35 лет).

- «Организация праздников хорошая, блины дают, когда в Масленицу, сжигание чучела. В день семьи-любви дарят какие-то мелкие подарки, пусть даже какие-то бумажные выдают, все равно это приятно... То есть в этом плане все организовано хорошо» (женщина, 36-55 лет).

В целом участники фокус-групповой дискуссии удовлетворены инфраструктурой и уровнем благоустроенности городских парков. Респонденты отмечали достаточное количество точек для санитарно-гигиенических нужд и общественного питания: «Вся инфраструктура в парке есть и руки где помыть, перекусить, этого вполне достаточно, а развлечения и интересы каждый найдет по себе» (мужчина, 36-55 лет).

Единодушное мнение посетителей о значительных улучшениях в состоянии современных парков и развитии в них инфраструктуры весьма показательно в контексте оценки возможностей парка для массового оздоровительного отдыха. Тем не менее в процессе фокус-группового интервьюирования были высказаны отдельные замечания к функционированию парков и предложены определенные меры, способствующие благоустройству территории московских парков. В частности, современным посетителям не хватает в парке некоторых элементов современной жизни. К ним относятся: доступ к беспроводным сетям связи (интернет-коммуникации), хорошее покрытие зоны мобильной связи. В отдельных случаях были высказаны пожелания о 
привнесении лучших практик и мировых тенденций отдыха в парки: беговые и велодорожки (разметка), тренажеры, занятия на открытом воздухе, наличие спорт-инструкторов, группы для занятий йогой и спортом на постоянной основе.

\section{ЗАКЛЮЧЕНИЕ}

На основании ответов участников фокус-групп, можно сделать вывод о том, что парки города на сегодняшний день являются привлекательным местом отдыха, прежде всего, для жителей близлежащих домов и улиц (района), для разных целей: прогулок с детьми, местом для занятия спортом, культурными развлечениями, массовыми праздниками, сезонными видами развлечений.

Подводя общие итоги, обратим внимание на следующие результаты:

- парки отчасти выступают как альтернатива даче;

- посетители больше предпочитают пассивный отдых, чем активный;

- проявляется стремление к комфорту, много внимания уделяется работе гаджетов в природной зоне парка (вай-фай, зарядка, пуфики, крыша и т. п.);

- посетители готовы участвовать в организованных мероприятиях, однако самостоятельно заниматься не хотят (несмотря на оборудованные спортивным инвентарем площадки, парки не стали зоной для регулярных физкультурно-оздоровительных занятий).

Проанализированные особенности поведения посетителей московских парков свидетельствуют о неполном освоении ресурсов парка для реализации оздоровительно-рекреационных практик в сфере досуга. Нельзя не отметить потребительскую ориентацию на виды досуга в парке как отражение общей тенденции современного общества «потребления». Однако потребительское поведение, ориентированное на пассивный комфортный отдых, далеко не всегда способствует сохранению и укреплению здоровья. Трудно не согласиться с мнением академика РАН А. В. Решетникова: «Здоровье можно считать даром природы, но от человека и от общества зависит сохранится, умножится или растратится этот бесценный дар» (Решетников, 2006: 65).

Подчеркнем, что полученные результаты, как и опыт применения качественной методологии для изучения феномена свободного времени, могут быть полезны для различных направлений медико-социологических исследований с целью оптимизации рекреационного поведения населения крупных городов и развития сферы досуговых учреждений, способствующих оптимизации здоровьесбережения граждан. 
СПИСОК ЛИТЕРАТУРЫ

А на досуге мы танцуем буги-вуги? (2017) [Электронный ресурс] // ВЦИОМ. Пресс-выпуск № 3524 от 29 ноября 2017 г. URL: https://wciom.ru/index.php?id=236\&uid=116559 [архивировано в WaybackMachine] (дата обращения: 13.03.2018).

Государственная программа города Москвы «Развитие городской среды» (2017) [Электронный ресурс] // Официальный сайт мэра Москвы. URL: https://mos.ru/upload/documents/docs/142-PP.pdf [архивировано в WaybackMachine] (дата обращения: 13.03.2018).

Решетников, А. В. (2006) Социология медицины : учебник. М. : ГЭОТАР-Медиа. 256 с.

Самым популярным видом досуга москвичи назвали прогулки на свежем воздухе (2016) [Электронный ресурс] // Информационное агентство России «TACC». 17 октября. URL: http://tass.ru/moskva/3710549 [архивировано в WaybackMachine] (дата обращения: 13.03.2018).

Социологическая энциклопедия (2003) : в 2 т. / Национальный общественно-научный фонд / Руководитель научного проекта Г. Ю. Семигин; гл. ред. В. Н. Иванов. М. : Мысль. Т. 1. 694 с.

Тощенко, Ж. Т., Цветкова, Г. А. (2012) Социология труда : учебник для вузов. М. : Центр социального прогнозирования и маркетинга. 464 с.

Дата поступления: 14.03.2018 2.

Лебедь Ольга Леонидовна - кандидат социологических наук, доцент кафедры социологии медицины, экономики здравоохранения и медицинского страхования Института социологии, психологии и гуманитарных наук Первого Московского государственного медицинского университета имени И. М. Сеченова Минздрава России. Адрес: 119435, г. Москва, ул. Россолимо, д. 11 стр. 2. Тел.: +7 (499) 246-12-52. Эл. адрес: lebed_olga@mail.ru

Пинчук Антонина Николаевна - научный сотрудник Института социально-политических исследований Российской академии наук. Адрес: 119333, г. Москва, ул. Фотиевой, д. 6, корп. 1. Тел.: +7 (499) 530-28-84. Эл. адрес: antonina.pinchuk27@bk.ru

Ляликова Софья Викторовна - старший лаборант кафедры социологии семьи и демографии социологического факультета Московского государственного университета имени М. В. Ломоносова. Адрес: 119234, г. Москва, Ленинские горы, д. 1, стр. 33. Тел.: +7 (495) 939-50-60. Эл. адрес: sofia_lyalikova@outlook.com

Lebed Olga Leonidovna, Candidate of Sociology, Associate Professor, Department of Sociology of Medicine, Health Economics and Medical Insurance, In- 
stitute of Sociology, Psychology and the Humanities, I. M. Sechenov First Moscow State Medical University, Ministry of Health of the Russian Federation. Postal address: Bldg. 2, 11 Rossolimo St., 119435 Moscow, Russian Federation. Tel.: +7 (499) 246-12-52. E-mail: lebed_olga@mail.ru

Pinchuk Antonina Nikolaevna, Researcher, Institute of Socio-Political Research, Russian Academy of Sciences. Postal address: Bldg. 1, 6 Fotievoi St., 119333 Moscow, Russian Federation. Tel.: +7 (499) 530-28-84. E-mail: antonina.pinchuk27@bk.ru

Lyalikova Sofia Viktorovna, Senior Laboratory Assistant, Department of Family Sociology and Demography, Faculty of Sociology, Lomonosov Moscow State University. Postal address: Bldg. 33, 1 Leninskie Gory, 119234 Moscow, Russian Federation. Tel.: +7 (495) 939-50-60. E-mail: sofia_lyalikova@out$\underline{\text { look.com }}$

Для цุитирования:

Лебедь О. Л., Пинчук А. Н., Ляликова С. В. Свободное время столичных жителей в условиях современной реальности: отдых в парковых зонах города Москвы [Электронный ресурс] // Горизонты гуманитарного знания. 2018. № 2. C. 74-85. URL: http://journals.mosgu.ru/ggz/article/view/763 (дата обращения: дД.мм.гггг). DOI: 10.17805/ggz.2018.2.7 